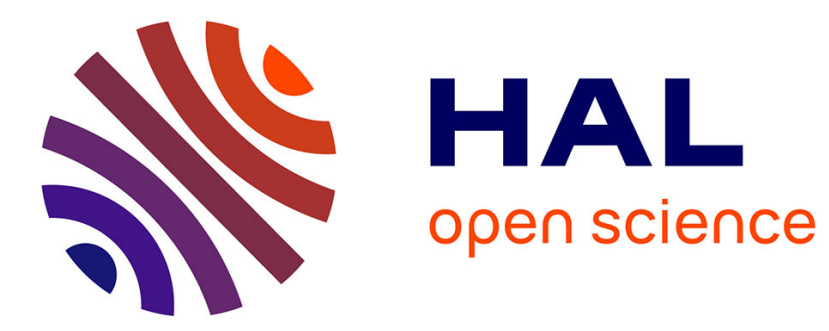

\title{
Can Life Emerge from Synthetic Polymers?
}

Jean-François Lutz

\section{To cite this version:}

Jean-François Lutz. Can Life Emerge from Synthetic Polymers?. Israel Journal of Chemistry, 2019, Rosarium Philosophorum - Macromolecules, 60 (1-2), pp.151-159. 10.1002/ijch.201900110 . hal02413003

\section{HAL Id: hal-02413003 \\ https://hal.science/hal-02413003}

Submitted on 30 Dec 2020

HAL is a multi-disciplinary open access archive for the deposit and dissemination of scientific research documents, whether they are published or not. The documents may come from teaching and research institutions in France or abroad, or from public or private research centers.
L'archive ouverte pluridisciplinaire HAL, est destinée au dépôt et à la diffusion de documents scientifiques de niveau recherche, publiés ou non, émanant des établissements d'enseignement et de recherche français ou étrangers, des laboratoires publics ou privés. 


\title{
Can Life emerge from synthetic polymers?
}

\author{
Jean-François Lutz*
}

Université de Strasbourg, CNRS, Institut Charles Sadron, UPR22, 23 rue du Loess, 67034 Strasbourg Cedex 2, France. E-mail: jflutz@unistra.fr

Published in Israel Journal of Chemistry, 60, 151-159 (2020)

https://doi.org/10.1002/ijch.201900110 
Abstract. Synthetic chemistry has drastically progressed during the last few decades. Like in DNA, it is now possible to synthesize abiotic macromolecules with precisely-controlled sequences of monomers. Artificial systems allowing hybridization and information transfer have been described. Simple metabolism models have also been prepared and investigated. Thus, the creation of minimal artificial life forms appears as a (still relatively far) but possibly reachable objective. In this context, the aim of the present essay is to discuss recent achievement and future challenges towards man-induced abiogenesis. In terms of polymer design, a synthetic macromolecule that would support Life as DNA do would require at least all the following properties: (i) information-storage capacity, (ii) information-transfer ability and (iii) the possibility to evolve through molecular mutations. Recent advances in that direction are summarized herein. However, Life is not only a matter of macromolecular design. In order to operate, a self-replicator shall co-exist with other molecules in non-equilibrium conditions. Hence, systems chemistry aspects are also discussed in this essay. 


\section{Introduction}

About 3.5-4 billion years ago, Life has emerged on Earth (Figure 1). Biological Life is primarily operated by sequence-defined polymers, which are nucleic acids (DNA and RNA) and proteins. ${ }^{[1]}$ Although a large amount of research has been dedicated to prebiotic chemistry and abiogenesis, scenarios leading to the formation of these polymers and ultimately to the emergence of the first unicellular marine organisms are still actively debated. The reader is therefore directed to classical reviews for detailed information on this broad topic. ${ }^{[2]}$ In brief, since the Miller experiment that has evidenced the formation of some biological monomers in laboratory conditions mimicking prebiotic Earth environment, ${ }^{[3]}$ it is believed that Life has emerged from a primordial chemical soup. ${ }^{[4]}$ Alternatives theories such as panspermia, which suggests that Earth was seeded through collisions with asteroids, meteors and comets, are nowadays less prominent.

Even if the emergence of Life is not fully explained, molecular biology is very well understood ${ }^{[5]}$ DNA is a self-replicating polymer that stores genetic information in the form of a controlled sequence of monomers and enables information transfer from generation to generation. It is also prone to rare but possible sequence variations (i.e. mutations), which allow Evolution through natural selection to take place. ${ }^{[6]}$ This molecular interpretation of Darwinian Evolution is supported by numerous works including Dawkins' popular theory of the selfish gene. ${ }^{[7]}$ Through Evolution and self-organization, ${ }^{[8]}$ complex living forms have gradually emerged (Figure 1). Over very long timescales (typically a few billion years in the case of Earth), this process may lead to the emergence of thinking species such as Humans. Interestingly, such species may start to perform intentional Chemistry and to understand how to transform their environment. This creates a rupture point in the chemical evolution continuum of the Universe that I coined as "thinking-species chemistry" in an earlier essay. ${ }^{[9]}$ Indeed, thinking species can synthesize and produce molecules that have not been generated by prebiotic chemistry and biology. They are therefore chemodiversity accelerators. For instance, Humans synthesize actively non-biological polymers for about a hundred years. ${ }^{[10]}$ In general, man-made macromolecules are less structurally-defined than biological polymers. Most of them are polydisperse; i.e. they have non-uniform molecular structures. Yet, as already pointed out decades ago by Staudinger, synthetic polymers are interesting models to understand Life and 
biology. ${ }^{[11]}$ In fact, these models have progressively become more and more refined over the last thirty years. ${ }^{[12]}$ Indeed, it is nowadays possible to control accurately the chain-length and monomer sequence of synthetic macromolecules. ${ }^{[1]}$ Furthermore, synthetic hybridization ${ }^{[13]}$ as well rudimentary replication and translation processes have been described. ${ }^{[14]}$

In this context, it is worth asking the following question: will synthetic macromolecules ever lead to Life ${ }^{[15]}$ In other words, is it possible to conceive non-DNA self-replicators leading to rudimentary life forms $?^{[16]}$ Considering recent progress in Chemistry, this is conceivable. Life has already emerged from polymers and it might be possible to make it artificially. However, creating a viable metabolism is not only a matter of polymer synthesis but also of non-equilibrium thermodynamics and systems chemistry. All these aspects are critically discussed in the present essay.

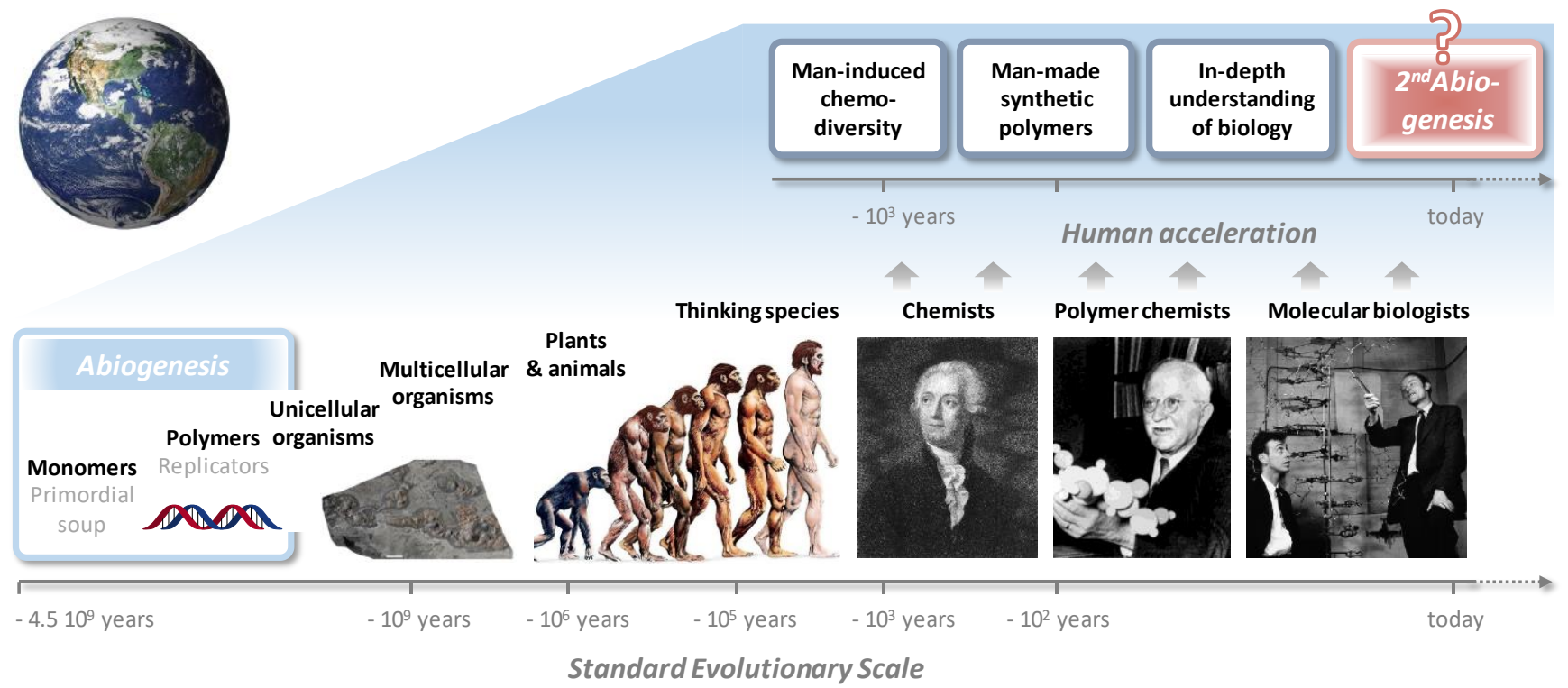

Figure 1. Simplified summary of the emergence and evolution of Life on Earth. The advent of thinking-species that can perform intentional chemistry is a breakpoint in the chemical evolution continuum of the planet. It increases chemodiversity and may lead to an induced abiogenesis

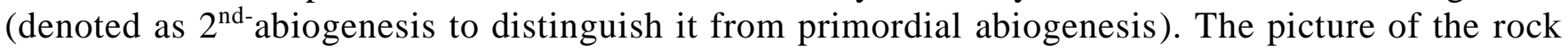
including fossils of multicellular organisms is reprinted with permission from reference [17]. The portraits show from left to right Antoine de Lavoisier (1743-1794), Hermann Staudinger (18811965) as well as James Watson (1928-) and Francis Crick (1916-2004). 


\section{What is a Life-supporting polymer?}

Before discussing the Life-supporting ability of synthetic polymers, it is mandatory to understand which molecular features allow a macromolecule such as DNA to carry Life. First of all, it shall be reminded that the terms "Life", "alive" and "living" are prone to different interpretations and, therefore, the reader is directed to prior literature discussing the definition of Life. ${ }^{[18]}$ It shall also be clarified that polymers are probably not the only options for creating artificial Life. Other chemical, biological or technological systems can be conceived. However, since terrestrial Life is operated by a polymer, which is DNA, it is plausible that other types of polymers could lead to Life. This reasoning is similar to the one used in exoplanets search. Extra-terrestrial Life is primarily expected on water-based planets (by analogy with Earth), although it could theoretically occur in other chemical environments. ${ }^{[16]}$

Table 1. Summary of the important features that make DNA a Life-supporting macromolecule. ${ }^{\text {[a] }}$

\begin{tabular}{ll}
\hline Property & Molecular reason \\
\hline Information & Controlled nucleotide sequence \\
Hybridization & Supramolecular base-pairing \\
Accessibility & Conformation, supercoiling \\
Self-replication & Templated enzymatic polymerization \\
Transcription & Enzymatic polymerization \\
Random & Depurination, deamination, dimerization \\
Repair & Mostly enzymatic \\
Epigenetics & Methylation, hydroxymethylation
\end{tabular}

[a] The content of this table is somehow subjective and is not meant to be absolute. ${ }^{[b]}$ The listed terms are only indicative examples of more complex mechanisms.

Table 1 lists eight important features that make DNA a unique Life-supporting macromolecule: (i) information storage in a controlled monomer sequence, (ii) duplex formation, which is a mandatory for replication (iii) topological accessibility, which permits to expose or not certain regions of the genome for replication and transcription, (iv) self-replication, ( $v$ ) translation into 
another type of messenger polymer, (vi) random mutations, which allow Evolution, (vii) possibility of repairing molecular damages, and (viii) dormant and active mode through epigenetics. It is anticipated that a synthetic polymer that would carry Life shall possess at least some (if not all) of these properties. For instance, to attain a rudimentary form of molecular Life, the possibility to store and transfer information seems to be the minimum required. Yet, such a minimal system shall also proceed in steady state conditions, which require constant chemical input and output. ${ }^{[19]}$ Another crucial feature would be, of course, the possibility for such a system to evolve. This implies that a synthetic self-replicator would be able to undergo random or controlled molecular variations through generations. In the following sections, the possibility to fulfil (or not) these requirements with synthetic polymers is discussed.

\section{Synthetic biology ${ }^{[20]}$}

An obvious path towards artificial Life is to synthesize and manipulate biopolymers such as DNA in the laboratory. In such approaches, the principles of molecular biology are used as such or are slightly modified. In other words, self-replicating macromolecules are not designed from the scratch but are derived from existing natural models. Thus, such studies are usually more related to biology than chemistry. However, these approaches permit to understand what kind of molecular variations are tolerated by living systems. Synthetic biology is a very broad field of research and only selected aspects are discussed in the following sub-sections.

\subsection{Natural nucleic acids}

\subsubsection{Laboratory synthesis of DNA}

Sequence-defined DNA and RNA can be synthesized in the laboratory using chemical $^{[21]}$ or enzymatic $^{[22]}$ protocols. DNA Chemical synthesis has begun in the 1960s and has been drastically facilitated by the discovery of phosphoramidite chemistry, ${ }^{[23]}$ a process than can be easily automatized ${ }^{[24]}$ and photocontrolled. ${ }^{[25]}$ It has been widely demonstrated that chemically-synthesized DNA segments can be 
incorporated into bacteria-expressible plasmids using recombinant DNA technology. In 2012, it was even demonstrated that a bacterial cell can be operated by an artificial genome that was entirely synthesized in a chemical laboratory. ${ }^{[26]}$ These example clearly demonstrate than Life can be partly or fully operated by lab-made macromolecules. However, these results have been obtained with man-made polymers that have the same molecular structure as biological DNA.

\subsubsection{In vitro replication}

Nucleic acids replication and transcription can be performed in vitro. ${ }^{[2]}$ For instance, the widespread polymerase chain reaction (PCR) is a biological DNA amplification method that is routinely performed in the laboratory. ${ }^{[28]}$ Non-enzymatic DNA replication and DNA $\rightarrow$ RNA transcription have also been widely studied, as described in details in recent reviews. ${ }^{[1,29]}$ The complementarity between RNA and peptide nucleic acids (PNA) was also reported. ${ }^{[30]}$ Even if they are polyamides, PNA oligomers can act as templates for RNA synthesis and vice versa. It was also recently demonstrated that DNA can act as a template for the synthesis of non-natural sequence-defined polymers (i.e. artificial translation). ${ }^{[14 \mathrm{~d}]}$ In this example, PNA adapters were used as intermediates to translate the sequence information of DNA into non-natural sequences. All these studies indicate that the essential information transfer mechanisms of Life can be recreated in a chemical laboratory.

\subsubsection{Protocells including minimal metabolisms}

Although a self-replicating macromolecule such as DNA is essential to Life, the molecular machinery of living cells is by far more complex than the simplified mechanisms described in the previous sections. ${ }^{[31]}$ Indeed, cell membranes confine a large number of different molecules that are in constant dynamic interaction. Such a "society" of molecules is best described by the theory of complex systems. In this context, there are a large of number of studies dealing with the inclusion of simplified self-replicating mixtures (e.g. PCR) or other minimal metabolic models (e.g. enzymatic cascades) in the confined interior of vesicles, microcapsules or microgels. Such protocell models have mainly been built using preformed lipid-based or polymer-based vesicles, namely liposomes and polymersomes. ${ }^{[32]}$ However, the formation 
of coacervates is also believed to have played a role in the origin of Life and therefore interesting examples of membrane-free protocells have been reported. ${ }^{[33]}$ The in situ self-organization of lipids (i.e. membrane formation) on the surface of coacervates droplets has also been observed. ${ }^{[34]}$ All these examples indicate that in vitro replication and transcription can be performed in artificial protocells.

\subsection{Nucleic acids analogues}

\subsubsection{Main-chain modifications}

A significant amount of research has been dedicated to the synthesis and the assessment of the biological properties of nucleic acids that slightly differ from natural ones (i.e. so-called nucleic acids analogues). ${ }^{[29]}$ For instance, xeno nucleic acids (XNA) have a main chain structure that differ from the ribophosphate backbone of natural DNA and RNA. Threose nucleic acids (TNA), locked nucleic acids (LNA) and morpholinos are typical examples of XNA. Among all reported examples, PNA, initially described by Nielsen and coworkers, ${ }^{[35]}$ have been shown to have a remarkable biological activity ${ }^{[36]}$ and are therefore used in various medical applications. More recently, Holliger and coworkers have evidenced that Darwinian evolution and heredity are not restricted to DNA and RNA but can also be attained with different types of XNA. ${ }^{[37]}$ It was also reported that some of these polymers can catalyze some chemical transformations like ribozymes do. ${ }^{[38]}$

\subsubsection{Side-chain modifications}

Besides main-chain modifications, numerous studies have been devoted to the synthesis and properties of nucleic acids containing non-natural nucleobases (i.e. side-chain modifications). ${ }^{[29,39]}$ In particular, various types of non-canonical nucleotides have been studied in in vitro enzymatic replication. For instance, Romersberg and coworkers have reported that non-natural base-pairs can be recognized by the biological replication machinery. ${ }^{[40]}$ More recently, an expanded genetic alphabet containing 8 symbols (instead of 4 in DNA and RNA) has been described by Benner and coworkers (Figure 2). ${ }^{[41]}$ Remarkably, it has been shown that such 8-bases DNA still exhibit a biological behavior and can be for instance 
transcribed into a corresponding RNA structure. These examples evidence that the basic features of Life (i.e. information transfer, mutability, evolvability) can be preserved after performing main-chain or sidechain modifications in nucleic acids.
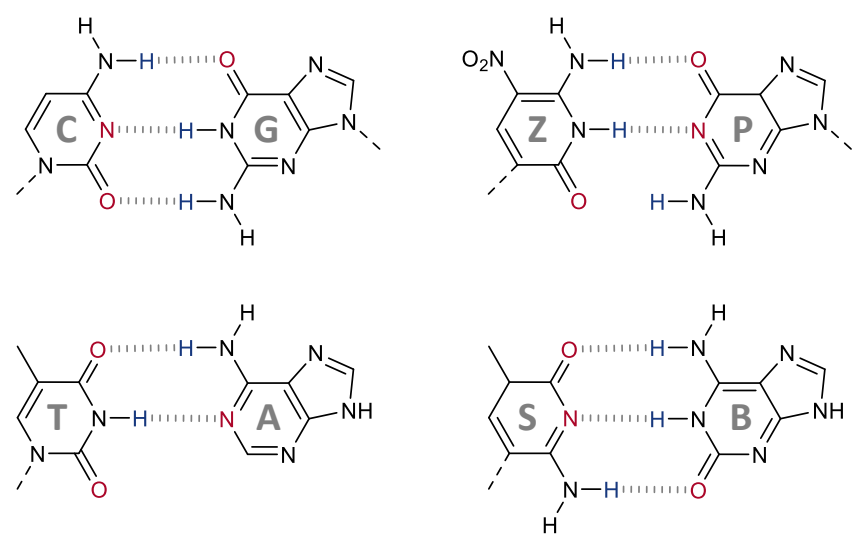

Figure 2. Expanded genetic alphabet containing eight different nucleobases, forming four orthogonal base pairs. The atoms highlighted in red and blue indicate hydrogen-bond acceptor and donor sites, respectively. Redrawn from reference ${ }^{[41]}$.

\section{Synthetic chemistry}

Addressing synthetic Life from a non-biological point of view is by far more challenging than working with genuine- or slightly-modified biological systems. Indeed, taking into account all available building blocks and reactions in synthetic chemistry, the search space is extremely large. However, over the last decades, significant progress has been made for the synthesis of abiotic polymers with controlled primary structure (i.e. monomer sequence) and secondary structure (i.e. single chain folding, strand hybridization). Furthermore, self-replication has been obtained with small abiotic molecules. These advances are described in the following sub-sections.

\subsection{Controlled information sequences}

Monomer sequence control is the solution found by Nature to store information at the molecular scale. ${ }^{[1]}$ Most of man-made synthetic copolymers (i.e. composed of two or more different monomers) do not have controlled primary structures because they are synthesized by statistical copolymerization methods such 
biochemistry in the 1950s and 1960s, efficient multistep synthetic approaches have been introduced for the preparation of sequence-defined proteins and nucleic acids ${ }^{[42]}$ In such multistep-growth approaches, ${ }^{[12]}$ monomers are usually attached one-by-one to a growing chain, which is time-consuming. Thus, these syntheses are most of the time performed on a solid-phase support, ${ }^{[1]}$ which simplifies and shortens experimental procedures. Starting about thirty years ago, multistep synthesis has also been used to prepare non-natural sequence-defined bio-oligomers, such as peptidomimetics and peptoids. ${ }^{[1,43]}$ Afterwards, a wide variety of fully-synthetic (i.e. structurally-unrelated to natural polymers) sequence-defined polymers have been synthesized and reported. ${ }^{[4]}$ In particular, starting about five years ago, ${ }^{[45]}$ it has been demonstrated that abiotic informational polymers can be prepared by solid-phase iterative chemistry. ${ }^{[46]}$ Hence, this essential particular property of Life-supporting polymers (Table 1) can now be easily recreated in synthetic systems. Yet, for the moment the chain-length of such macromolecules is limited to about 100 information residues, ${ }^{[47]}$ which is much shorter than in natural polymers. To give an idea of the gap between biological and non-biological polymers, the human chromosome 1 is, for example, composed of two hybridized DNA chains, each of which containing a perfectly defined sequence of 248956422 monomers (i.e. more than 248 million). Nevertheless, medium-size manmade informational polymers can be synthesized and routinely utilized.

\subsection{Synthetic hybridization}

As listed in Table 1, strand hybridization is a key property in molecular biology. Several research groups have described the formation of abiotic supramolecular duplexes. Some of the earliest examples have been reported by Lehn and coworkers using either metal-ligand or hydrogen-bonding supramolecular interactions. ${ }^{[13 \mathrm{a}, 48]}$ Afterwards, other interesting studies have been reported by the groups of Gong, ${ }^{[13 \mathrm{~b}]}$ Yashima, ${ }^{[49]}$ Hunter, ${ }^{[13 c]}$ Scott ${ }^{[50]}$ and others. ${ }^{[51]}$ However, in most reported examples, the hybridization of two homopolymer strands was studied, which is the simplest situation that can be achieved. It can be obtained by either hybridizing the same strand (i.e. self-complementary homopolymer) or using two complementary homopolymers. Therefore, these systems do not allow orthogonal strand recognition. In 
order to achieve this, sequence-specific hybridization is mandatory. Sequence-specific duplexes can be obtained using defined sequences of two, four or eventually more complementary monomers. Yet, there are currently very few examples of synthetic oligomers that can undergo sequence-specific hybridization. $^{[13 \mathrm{~b}, 52]}$

\subsection{Self-replication and information transfer}

The ability of a macromolecule to copy itself and to transfer its information is crucial to Life. There is currently no man-made macromolecule that copy itself in the way DNA does. However, during the last thirty years, there has been significant research on the design of minimal replicating systems. ${ }^{[14 a, 53]}$ These pioneer studies, involving in most cases small model molecules, have been described in details in a recent review. ${ }^{[54]}$ Although rudimentary self-replication behaviors have been demonstrated, most of the reported systems do not allow transfer of coded information sequences as achieved by nucleic acids. ${ }^{[27]}$ In these context, there was earlier this year two interesting examples of sequence information transfer using dynamic $^{[14 b]}$ or covalent ${ }^{[14 c]}$ bonds between coded template and substrates. Yet, these examples were achieved with rather small information sequences (i.e. dimer or trimer) and much remains to be done to extend these concepts to long information sequences.
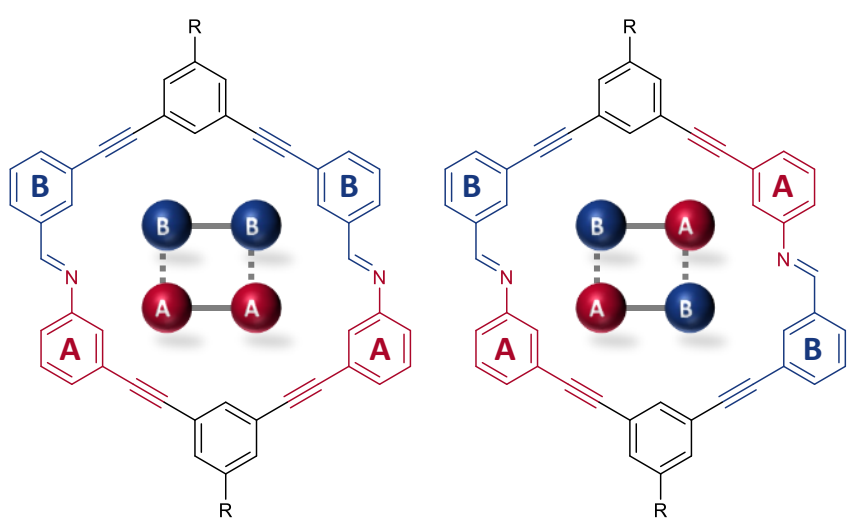

Figure 3. Examples of self-replicating cyclic molecules containing dynamic imine bonds. The red and blue spheres highlight the information sequences that are copied during the replication process. Redrawn from reference [14b]. 


\subsection{Synthetic mutations}

Mutability allows evolution. Indeed, in a self-replicating system, discrete molecular variations may lead to information content changes from generation to generation and therefore to an adaptive behavior. Since the self-replication of abiotic informational polymers has not been achieved yet, the mutability of synthetic polymers has not been investigated. However, it is already possible to perform discrete monomer modifications in synthetic information-containing macromolecules. For instance, our group has recently reported that light can be used as a simple trigger to induce molecular changes in sequence-coded poly(phosphodiester)s. ${ }^{[55]}$ Such a concept is inspired by irradiation-mediated mutagenesis and enables sitedirected mutations in synthetic polymers. In the future, such modifications could be used in conjunction with a self-replicating system to generate an evolutionary behavior in synthetic polymers. Yet, in a real evolvable polymer, such mutations shall not be site-directed but shall occur randomly (and rarely).

\section{Emergence vs. Intention}

As described in the previous pages, artificial macromolecular Life can be envisaged from two different standpoints: either tweaking existing biopolymers (synthetic biology) or preparing new types of polymers using non-natural building-blocks and reactions (synthetic chemistry). Addressing Life from the latter approach is much more challenging, taking into account the number of building blocks and reactions that are available to chemists. Moreover, given the numerous molecular parameters (e.g. interdistance between coded monomer units, backbone stiffness, stereochemistry, secondary structure, affinities of different part of the molecule with the solvent... etc...) that could influence the behavior and physico-chemical properties of informational macromolecules, it is unreasonable to think that all aspects can be solved with a single lucky design, even with the help of computational chemistry. In fact, an artificial Life-supporting macromolecule shall probably not be entirely conceived. As learned from Nature, it shall better emerge as a viable and adapted solution from a component mixture under selective pressure. In the paragraph, recent 
efforts for preparing artificial metabolisms that proceed in non-equilibrium thermodynamic conditions are briefly discussed.

\subsection{Systems Chemistry}

Life does not occur at thermodynamic equilibrium. ${ }^{[19]}$ Indeed, living organisms are constantly exchanging energy and matter with their environment. Therefore, as a matter of fact, a Lifesupporting macromolecule is by itself not sufficient to spark Life. In other words, having a polymer that fulfil all criteria listed in Table 1 is not enough to obtain living matter. For instance, DNA can be stored as inanimate matter in archaeological remains or in a laboratory flask. To trigger and support Life, DNA shall be involved in a metabolic process. In this context, there was recently an increased interest for the burgeoning field of systems chemistry, which focuses on the comprehension of complex molecular networks (e.g. dynamic combinatorial libraries, oscillating reactions, autocatalytic compounds). ${ }^{[56]}$ For instance, several minimal self-replicating systems (see section 4.3) but also more complex networks of synthetic replicators have been studied. ${ }^{[57]}$ However, in most cases, these systems end up in thermodynamically or kinetically-trapped products. An elegant example of chemically-fuelled self-replicating system was reported earlier this year by Fletcher and coworkers. ${ }^{[58]}$ This system involves disulfide low molecular weight surfactants and does not allow information transfer. Yet, although far from macromolecular science, it demonstrates that simple metabolic cycles can be attained with abiotic components.

\subsection{Toward evolutionary systems}

As described in the previous section, minimal chemical systems that self-replicate have been reported. However, in order to exhibit a true Darwinian evolutionary behavior, a molecule shall not only copy itself but also be able to mutate, as summarized in Table 1 . Hence, a rudimentary proofof-principle of artificial Chemical Life would require the design of a macromolecular informational system, in which both information transfer and mutations are achievable. Although technically conceivable, such a system has not been reported to date with abiological macromolecules. 
Nevertheless, it would permit to derive from initial intentional design toward the emergence of adapted informational sequences and properties. In other words, such a macromolecular system would become truly adaptive. ${ }^{[59]}$

\subsection{Accelerated progress through Human selection}

Sequence-controlled polymers constitute a particularly vast domain of investigation for chemists because the number of possible molecules can be dramatically high and exceed Human experimental and calculation capabilities. ${ }^{[1]}$ For proteins (which is only one type of macromolecule), it has already been pointed out long time ago by Staudinger that the number of isomers of a moderate-size sequence exceeds the number of water molecules in the seas of Earth. ${ }^{[60]}$ Actually, it even exceeds the number of available atoms in the observable Universe. ${ }^{[16]}$ Including man-made sequence-defined polymers in the search space will increase even further the number of possibilities. Thus, progress and discovery shall be somehow guided. For a polymer capable of Darwinian evolution (vide supra), change can operate under the selective pressure of environmental conditions. However, such

processes are usually very slow, even though they can be artificially accelerated. ${ }^{[61]}$ The selection of promising molecules by Human chemists is another important parameter for guiding discovery and narrowing down the search space. With the help of intuition and reasoning, Humans may: (i) first synthesize and screen a restricted number of promising molecules, (ii) select the most promising structures and (iii) involve them in a metabolic process leading to further evolution (vide supra). In other words, a subtle combination of macromolecular design and systems chemistry could be the key toward the development of artificial Life-supporting macromolecules.

\section{Artificial mimics of other biological functions}

The core discussion of the present Essay is about the realization of artificial Life-supporting macromolecules (i.e. polymers that store information, transfer information and evolve). Yet, as pointed out by one of the reviewers of this manuscript, polymer science offers many other 
possibilities to mimic biological behaviors. For instance, lipid cell-membranes can be replaced by block copolymer membranes, as discussed in section 3.1.3. Moreover, the compartmentalization of such polymer-based membranes leading to the formation of artificial organelles has been described. ${ }^{[62]}$ The catalytic activity of enzymes has also been mimicked with synthetic polymers, such as single-chain nanoparticles. ${ }^{[63]}$ There is also an abundant literature, which will not be discussed herein, about synthetic polymers mimicking the properties of polysaccharides and other types of proteins than enzymes. Thus, fully artificial cell-mimics could be envisioned, although it is probably not a realistic aim for this century. Indeed, preparing an artificial cell, entirely operated by man-made molecular components, appears improbable based on the current state-of-the-art. Thus, the first steps toward polymer-based artificial Life shall probably involve minimal model systems, as discussed in the next section.

\section{How far is polymer-based artificial Life?}

Significant research efforts have already been made to synthesize abiotic (macro)molecules exhibiting some of the Life-relevant properties listed in Table 1. Therefore, it is already possible to store information in the comonomer sequence of a synthetic polymer, to form duplexes from nonnatural polymer strands and to replicate to some degree small molecules. However, none of the examples discussed in previous pages are describing molecules that could successfully support Life. There are several reasons for that. As previously mentioned, the first main reason is that, in terms of possible building blocks and chemical reactions, the search space is ex tremely wide. For instance, all the systems described in sections 4 and 5 were somehow obtained with different types of molecules. Consequently, there is currently no non-nucleic acid molecule that combine several (i.e. at least two or three) properties listed in Table 1. Another important drawback is that most of the examples listed in section 4 have been obtained with small molecules. In fact, the transition from low molecular weight models to true informational macromolecules (i.e. oligomers or polymers containing at least 5-10 monomer units) is far from being trivial. Therefore, the answer the question 
written in the title of this section is: polymer-based artificial Life was probably never that close but still relatively far. In order to achieve it, progress remains to be done regarding the synthesis and mutability of informational macromolecules and their implementation in out-of-equilibrium metabolic networks.

\section{Scientific and philosophical outlook}

As discussed in the present text and in an earlier essay, ${ }^{[9]}$ Humans are polymer-operated thinking species that have emerged through many years of Darwinian natural selection. Interestingly, and maybe ironically, these "polymer-operated machines" may succeed someday in creating new types of self-replicating polymers (i.e. different from those of Earth's biology) that may lead to new Life forms. This is, of course, not for tomorrow. As summarized in sections 5 and 6, there are still many hurdles ahead. The will to create a Life-supporting macromolecule by complete chemical design is maybe one of them. Synthetic Life may well emerge from a mixture of carefully-designed components but may also happen from a random pool of chemicals, as learned from the History of our Universe. Here, interesting experiments may be imagined for the next generations and centuries. For instance, if Humans succeed someday in creating efficient evolvable self-replicators, directed panspermia could be tried. ${ }^{[64]}$ If the search for water-based exoplanets becomes routine someday, it might be conceivable to send seeding spaceships to sterile planets. These spaceships could contain cocktails of basic biological synthons (i.e. nucleotides, lipids, amino acids) but the same experiment could also be performed with man-made molecules. In other words, a sterile isolated planet could be used as a "closed flask" for artificial Life experiments (in planeto chemistry). Although all the above considerations sound today as pure science-fiction, recent NASA (as well as other private companies) efforts for studying and sending DNA to space show that such goals are not so unrealistic on

a long term. There are, of course, major ethical issues regarding the creation of artificial Life systems and the fact to spread them on Earth or through the Universe. Such ideas are definitively provocative in the early $21^{\text {st }}$ century where conservationist and preservationist ideas currently dominate. However, we shall 
ask ourselves is the faith of the Universe is to be preserved and or to Evolve? If the latter answer is the right one, polymer-based artificial Life may become someday a reality.

\section{Acknowledgements}

J.-F.L. thanks the CNRS and the excellence network Chemistry of Complex Systems (LabEx CSC) for recurrent financial support.

\section{References}

[1] J.-F. Lutz, M. Ouchi, D. R. Liu, M. Sawamoto, Science 2013, 341, 1238149.

[2] a) L. E. Orgel, Crit. Rev. Biochem. Mol. Biol. 2004, 39, 99-123; b) A. Eschenmoser, Tetrahedron 2007, 63, 12821-12844; c) K. Ruiz-Mirazo, C. Briones, A. de la Escosura, Chem. Rev. 2014, 114, 285-366; d) S. Rasmussen, L. Chen, M. Nilsson, S. Abe, Artif. Life 2003, 9, 269-316; e) I. A. Chen, Science 2006, 314, 1558.

[3] S. L. Miller, Science 1953, 117, 528.

[4] A. I. Oparin, Proiskhozhdenie zhizni, Moskovskii Rabochii, Moscow, 1924.

[5] J. M. Berg, J. L. Tymockzo, G. J. Gatto Jr., L. Stryer, Biochemistry, $8^{\text {th }}$ revised ed., W. H. Freeman, New York, 2015.

[6] M. Kimura, Nature 1968, 217, 624-626.

[7] R. Dawkins, The selfish gene, Oxford University Press, 1976.

[8] J.-M. Lehn, Angew. Chem., Int. Ed. 2013, 52, 2836-2850.

[9] J.-F. Lutz, Chem 2017, 2, 155-156.

[10] This Rosarium Philosophorum special issue of Israel Journal of Chemistry coincides with the $100^{\text {th }}$ anniversary of the coinage of the term "Polymerization" by Hermann Staudinger: H. Staudinger, Ber. Dtsch. Chem. Ges. 1920, 53, 1073-1085

[11] H. Staudinger, Makromol. Chem. 1947, 1, 7-21.

[12] J.-F. Lutz, J.-M. Lehn, E. W. Meijer, K. Matyjaszewski, Nat. Rev. Mater. 2016, 1, 16024. 
[13] a) V. Berl, I. Huc, R. G. Khoury, M. J. Krische, J.-M. Lehn, Nature 2000, 407, 720; b) B. Gong, Acc. Chem. Res. 2012, 45, 2077-2087; c) A. E. Stross, G. Iadevaia, C. A. Hunter, Chem. Sci. 2016, 7, 94-101.

[14] a) J. M. A. Carnall, C. A. Waudby, A. M. Belenguer, M. C. A. Stuart, J. J. P. Peyralans, S. Otto, Science 2010, 327, 1502; b) K. R. Strom, J. W. Szostak, N. Prywes, J. Org. Chem. 2019, 84, 37543761; c) D. Núñez-Villanueva, M. Ciaccia, G. Iadevaia, E. Sanna, C. A. Hunter, Chem. Sci. 2019, 10, 5258-5266; d) J. Niu, R. Hili, D. R. Liu, Nat. Chem. 2013, 5, 282-292.

[15] The possibility to create alternative chemical Life, which is the topic discussed in this essay, shall be distinguished from the development of artificial intelligence, which is a drastically different question.

[16] S. A. Benner, A. Ricardo, M. A. Carrigan, Curr. Opin. Chem. Biol. 2004, 8, 672-689.

[17] A. E. Albani, S. Bengtson, D. E. Canfield, A. Bekker, R. Macchiarelli, A. Mazurier, E. U. Hammarlund, P. Boulvais, J.-J. Dupuy, C. Fontaine, F. T. Fürsich, F. Gauthier-Lafaye, P. Janvier, E. Javaux, F. O. Ossa, A.-C. Pierson-Wickmann, A. Riboulleau, P. Sardini, D. Vachard, M. Whitehouse, A. Meunier, Nature 2010, 466, 100.

[18] a) E. Schrödinger, What is Life?, The McMillan Company, New York, 1945; b) C. E. Cleland, C. F. Chyba, Origins Life Evol. Biosphere 2002, 32, 387-393; c) S. A. Benner, Astrobiology 2010, 10, 1021-1030.

[19] E. D. Schneider, J. J. Kay, Math. Comput. Modell. 1994, 19, 25-48.

[20] There are different ways to interpret the terms Synthetic Biology as discussed in: S. A. Benner, Z. Yang, F. Chen, C.R. Chim. 2011, 14, 372-387. In the present Essay, it denotes the ability to prepare, transform and improve natural biological systems in Human laboratories.

[21] M. H. Caruthers, J. Biol. Chem. 2013, 288, 1420-1427.

[22] S. Palluk, D. H. Arlow, T. de Rond, S. Barthel, J. S. Kang, R. Bector, H. M. Baghdassarian, A. N. Truong, P. W. Kim, A. K. Singh, N. J. Hillson, J. D. Keasling, Nat. Biotech. 2018, 36, 645.

[23] S. L. Beaucage, R. P. Iyer, Tetrahedron 1992, 48, 2223-2311. 
[24] M. H. Caruthers, Science 1985, 230, 281-285.

[25] S. P. Fodor, J. L. Read, M. C. Pirrung, L. Stryer, A. T. Lu, D. Solas, Science 1991, 767-773.

[26] D. G. Gibson, J. I. Glass, C. Lartigue, V. N. Noskov, R.-Y. Chuang, M. A. Algire, G. A. Benders, M. G. Montague, L. Ma, M. M. Moodie, C. Merryman, S. Vashee, R. Krishnakumar, N. AssadGarcia, C. Andrews-Pfannkoch, E. A. Denisova, L. Young, Z.-Q. Qi, T. H. Segall-Shapiro, C. H. Calvey, P. P. Parmar, C. A. Hutchison, H. O. Smith, J. C. Venter, Science 2010, 329, 52.

[27] L. E. Orgel, Nature 1992, 358, 203-209.

[28] R. Saiki, D. Gelfand, S. Stoffel, S. Scharf, R. Higuchi, G. Horn, K. Mullis, H. Erlich, Science 1988, $239,487-491$.

[29] Y. Brudno, D. R. Liu, Chem. Biol. 2009, 16, 265-276.

[30] C. Bohler, P. E. Nielsen, L. E. Orgel, Nature 1995, 376, 578-581.

[31] a) J. W. Szostak, D. P. Bartel, P. L. Luisi, Nature 2001, 409, 387-390; b) J. Attwater, P. Holliger, Nat. Methods 2014, 11, 495.

[32] a) P. Walde, BioEssays 2010, 32, 296-303; b) N. P. Kamat, J. S. Katz, D. A. Hammer, J. Phys. Chem. Lett. 2011, 2, 1612-1623; c) K. Kurihara, M. Tamura, K.-i. Shohda, T. Toyota, K. Suzuki, T. Sugawara, Nat. Chem. 2011, 3, 775; d) K. Kurihara, Y. Okura, M. Matsuo, T. Toyota, K. Suzuki, T. Sugawara, Nat. Commun. 2015, 6, 8352.

[33] a) E. Sokolova, E. Spruijt, M. M. K. Hansen, E. Dubuc, J. Groen, V. Chokkalingam, A. Piruska, H. A. Heus, W. T. S. Huck, Proc. Natl. Acad. Sci. U.S.A. 2013, 110, 11692; b) M. Li, X. Huang, T. Y. D. Tang, S. Mann, Curr. Opin. Chem. Biol. 2014, 22, 1-11.

[34] T. Y. Dora Tang, C. Rohaida Che Hak, A. J. Thompson, M. K. Kuimova, D. S. Williams, A. W. Perriman, S. Mann, Nat. Chem. 2014, 6, 527.

[35] M. Egholm, O. Buchardt, P. E. Nielsen, R. H. Berg, J. Am. Chem. Soc. 1992, 114, 1895-1897.

[36] M. Egholm, O. Buchardt, L. Christensen, C. Behrens, S. M. Freier, D. A. Driver, R. H. Berg, S. K. Kim, B. Norden, P. E. Nielsen, Nature 1993, 365, 566-568. 
[37] V. B. Pinheiro, A. I. Taylor, C. Cozens, M. Abramov, M. Renders, S. Zhang, J. C. Chaput, J. Wengel, S.-Y. Peak-Chew, S. H. McLaughlin, P. Herdewijn, P. Holliger, Science 2012, 336, 341344.

[38] A. I. Taylor, V. B. Pinheiro, M. J. Smola, A. S. Morgunov, S. Peak-Chew, C. Cozens, K. M. Weeks, P. Herdewijn, P. Holliger, Nature 2015, 518, 427-430.

[39] a) A. A. Henry, F. E. Romesberg, Curr. Opin. Chem. Biol. 2003, 7, 727-733; b) G. T. Hwang, F. E. Romesberg, Nucleic Acids Res. 2006, 34, 2037-2045.

[40] D. A. Malyshev, K. Dhami, T. Lavergne, T. Chen, N. Dai, J. M. Foster, I. R. Correa, F. E. Romesberg, Nature 2014, 509, 385-388.

[41] S. Hoshika, N. A. Leal, M.-J. Kim, M.-S. Kim, N. B. Karalkar, H.-J. Kim, A. M. Bates, N. E. Watkins, H. A. SantaLucia, A. J. Meyer, S. DasGupta, J. A. Piccirilli, A. D. Ellington, J. SantaLucia, M. M. Georgiadis, S. A. Benner, Science 2019, 363, 884.

[42] a) P. T. Gilham, H. G. Khorana, J. Am. Chem. Soc. 1958, 80, 6212-6222; b) R. B. Merrifield, J. Am. Chem. Soc. 1963, 85, 2149-2154.

[43] a) R. N. Zuckermann, J. M. Kerr, S. B. H. Kent, W. H. Moos, J. Am. Chem. Soc. 1992, 114, 1064610647; b) C. Y. Cho, E. J. Moran, Cherry, J. C. Stephans, S. P. Fodor, C. L. Adams, A. Sundaram, J. W. Jacobs, P. G. Schultz, Science 1993, 261, 1303-1305.

[44] a) N. Badi, J.-F. Lutz, Chem. Soc. Rev. 2009, 38, 3383-3390; b) S. C. Solleder, R. V. Schneider, K. S. Wetzel, A. C. Boukis, M. A. R. Meier, Macromol. Rapid Commun. 2017, 38, 1600711; c) J. K. Szymański, Y. M. Abul-Haija, L. Cronin, Acc. Chem. Res. 2018, 51, 649-658.

[45] a) H. M. Colquhoun, J.-F. Lutz, Nat. Chem. 2014, 6, 455-456; b) T. T. Trinh, L. Oswald, D. ChanSeng, J.-F. Lutz, Macromol. Rapid Commun. 2014, 35, 141-145.

[46] a) A. Al Ouahabi, L. Charles, J.-F. Lutz, J. Am. Chem. Soc. 2015, 137, 5629-5635; b) R. K. Roy, A. Meszynska, C. Laure, L. Charles, C. Verchin, J.-F. Lutz, Nat. Commun. 2015, 6, 7237; c) M. G. T. A. Rutten, F. W. Vaandrager, J. A. A. W. Elemans, R. J. M. Nolte, Nat. Rev. Chem. 2018.

[47] A. Al Ouahabi, M. Kotera, L. Charles, J.-F. Lutz, ACS Macro Lett. 2015, 4, 1077-1080. 
[48] U. Koert, M. M. Harding, J.-M. Lehn, Nature 1990, 346, 339-342.

[49] E. Yashima, K. Maeda, H. Iida, Y. Furusho, K. Nagai, Chem. Rev. 2009, 109, 6102-6211.

[50] T. Wei, J. C. Furgal, J. H. Jung, T. F. Scott, Polym. Chem. 2017, 8, 520-527.

[51] a) M. Kurlemann, B. J. Ravoo, Beilstein J. Org. Chem. 2014, 10, 2428-2440; b) Y. Liu, F. C. Parks, W. Zhao, A. H. Flood, J. Am. Chem. Soc. 2018, 140, 15477-15486.

[52] a) A. Marquis, V. Smith, J. Harrowfield, J.-M. Lehn, H. Herschbach, R. Sanvito, E. Leize-Wagner, A. Van Dorsselaer, Chem. Eur. J. 2006, 12, 5632-5641; b) H. Ito, Y. Furusho, T. Hasegawa, E. Yashima, J. Am. Chem. Soc. 2008, 130, 14008-14015; c) A. E. Stross, G. Iadevaia, D. NúñezVillanueva, C. A. Hunter, J. Am. Chem. Soc. 2017, 139, 12655-12663.

[53] a) G. von Kiedrowski, Angew. Chem., Int. Ed. 1986, 25, 932-935; b) T. Tjivikua, P. Ballester, J. Rebek, J. Am. Chem. Soc. 1990, 112, 1249-1250; c) D. Sievers, G. von Kiedrowski, Nature 1994, 369, 221-224; d) D. H. Lee, J. R. Granja, J. A. Martinez, K. Severin, M. R. Ghadiri, Nature 1996, $382,525-528$.

[54] A. Vidonne, D. Philp, Eur. J. Org. Chem. 2009, 2009, 593-610.

[55] N. F. König, A. Al Ouahabi, L. Oswald, R. Szweda, L. Charles, J.-F. Lutz, Nat. Commun. 2019 , 10,3774 .

[56] a) R. F. Ludlow, S. Otto, Chem. Soc. Rev. 2008, 37, 101-108; b) J. R. Nitschke, Nature 2009, 462, 736.

[57] T. Kosikova, D. Philp, Chem. Soc. Rev. 2017, 46, 7274-7305.

[58] S. M. Morrow, I. Colomer, S. P. Fletcher, Nat. Commun. 2019, 10, 1011.

[59] a) J.-M. Lehn, Proc. Natl. Acad. Sci. U.S.A. 2002, 99, 4763-4768; b) J.-M. Lehn, Angew. Chem., Int. Ed. 2015, 54, 3276-3289.

[60] H. Staudinger, 1953.

[61] M. S. Packer, D. R. Liu, Nat. Rev. Genet. 2015, 16, 379. 
[62] a) R. J. R. W. Peters, I. Louzao, J. C. M. van Hest, Chem. Sci. 2012, 3, 335-342; b) A. F. Mason, N. A. Yewdall, P. L. W. Welzen, J. Shao, M. van Stevendaal, J. C. M. van Hest, D. S. Williams, L. K. E. A. Abdelmohsen, ACS Cent. Sci. 2019, 5, 1360-1365.

[63] a) T. Terashima, T. Mes, T. F. A. De Greef, M. A. J. Gillissen, P. Besenius, A. R. A. Palmans, E. W. Meijer, J. Am. Chem. Soc. 2011, 133, 4742-4745; b) N. Giuseppone, J.-F. Lutz, Nature 2011, $473,40-41$.

[64] F. H. C. Crick, L. E. Orgel, Icarus 1973, 19, 341-346. 